\title{
UN CONCEPTO NORMATIVO DE COHERENCIA PARA UNA TEORÍA DE LA ARGUMENTACIÓN JURÍDICA
}

\author{
Presentación y traducción de \\ Juan Carlos Velasco Arroyo
}

\section{Presentación}

esde hace algunos años se ha venido reflexionando sobre el derecho a partir de la teoría discursiva de Jürgen Habermas, empeño que ha acabado cristalizando -aunque no exclusivamente- en su última obra aparecida en 1992: Faktizität und Geltung. No es prematuro afirmar que la teoría crítica de la sociedad de Habermas ha dado un nuevo impulso a la teoría y sociología del derecho. Su original reflexión conjuga dos tipos de tratamiento frecuentemente separados: un análisis sociohistórico de la evolución del sistema jurídico y un análisis epistemológico del discurso jurídico. De este modo se indaga entre la relación entre la función social y la normatividad del derecho en las sociedades modernas, por una parte, y el estatuto epistemológico del discurso jurídico, por otra ${ }^{1}$. A este último aspecto se dedica el presente artículo.

Como no cabía menos de una teoría que postula la comunicación como el lugar natural de la razón en la elaboración de Faktizität und Geltung fueron importantes las intensas discusiones mantenidas en el seno de un seminario sobre Teoría del Derecho que tuvo lugar en la Universidad de Frankfurt entre 1985-1990, así como las distintas monografías de los jóvenes investigadores que participaron en el mismo, de tal modo que suministran un material imprescindible para la interpretación de aquella obra. Hasta el momento, en castellano sólo están disponibles los principales escritos de Robert Alexy, al que cabe el mérito de haber descubierto en Habermas un

${ }^{1}$ Cfr. Hervé Pourtois: «Théorie sociale et jugement juridique. A propos de J. Habermas et de Kl. Günther», en Archives de Philosophie du Droit, n. ${ }^{\circ} 37$ (1992), págs. 303-312. 
potencial teórico utilizable para sistematizar el enmarañado mundo de la argumentación jurídica. Sin embargo, no es a Alexy a quien Habermas se remite con mayor profusión en sus últimas obras, sino a Klaus Günter: tanto Die nachholende Revolution (1990) como Erläuterungen zur Diskurstheorie (1991) y Faktizität und Geltung (1992) incorporan ideas de este autor $y$, en concreto, del artículo que a continuación se traduce ${ }^{2}$. El maestro francfortiano recurre a Günther, sobre todo, para contrarrestar el elevado grado de abstracción -su universalismo ético- del que frecuentemente se ve acusado por sus críticos.

Entre los numerosos escritos sobre filosofía social y jurídica de Klaus Günther, un joven profesor de la Facultad de Derecho de la Universidad de Francfort, destaca su único libro: Der Sinn für Angemessenheit. Anwendungsdiskurse in Moral und Recht ${ }^{3}$. El sentido de la adecuación -así reza en castellano su título- no se revela sólo en seguir principios correctos en los casos prácticos, sino también en su aplicación imparcial atendiendo a todas las circunstancias especiales de cada caso. La tesis de este libro es que a pesar del peligro no desdeñable de caer en un relativismo, dada la necesidad postulada de mantenerse sensible al contexto, uno no ha de quedar excesivamente dependiente de él, pues tampoco en las situaciones de aplicación de normas se está autorizado a desistir del empleo de la razón práctica.

La apelación a una interpretación coherente del conjunto de normas disponibles en un contexto social determinado constituye, ciertamente, una manera de atenerse a razones también en los casos prácticos de aplicación de normas. John Rawls ya introdujo esta idea al considerar que la justificación de una concepción de la justicia «es cuestión del mutuo apoyo de muchas consideraciones y de que todo se ajuste conjuntamente en una visión coherente» ${ }^{4}$. Ronald Dworkin emplea un concepto análogo, el de «integridad», para designar la exigencia de compatibilizar normas jurídicas y comportamiento político, esto es, un requerimiento general para actuar «sobre una base de principios coherentes y únicos» 5 . Apoyándose críticamente en estos y otros antecedentes anglosajones, Günther ha articulado una

${ }^{2}$ Cfr. Jürgen Habermas: Die nachholende Revolution, Suhrkamp, Frankfurt, 1990 [existe versión castellana: La necesidad de revisión de la izquierda, Tecnos, Madrid, 1991]; Erläuterungen zur Diskurstheorie, Suhrkamp, Frankfurt, 1991; y Faktizität und Geltung, Suhrkamp, Frankfurt, 1992.

${ }^{3}$ Klaus Günther: Der Sinn für Angemessenheit. Anwendungsdiskurse in Moral und Recht, Suhrkamp, Frankfurt, 1988. Existe versión inglesa: The Sense of Appropiateness - Application Discourses in Morality and Law, State University of New York Press, Albany, 1993.

${ }^{4}$ John Rawls: Teoría de la justicia, Fondo de Cultura Económica, México, 1979, pág. 39 (cursivas de JCVA).

${ }^{5}$ Ronald Dworkin: El imperio de la justicia, Gedisa, Barcelona, 1988, pág. 125. 
concepción original de la coherencia de los sistemas normativos en la que también se incorporan productivamente elementos propios de la teoría habermasiana del discurso práctico.

En el texto que se ofrece traducido a continuación, «Ein normativer Begriff der Kohärenz» ${ }^{6}$, Günther recupera la idea, ya defendida con mayor detalle en su anterior libro, de que en los discursos prácticos generales es preciso distinguir entre discursos de fundamentación y discursos de aplicación, pues los criterios que sirven para dilucidar la validez de una norma no coinciden con los utilizados para indicar la adecuación de una norma válida a una determinada situación. El razonamiento práctico tiene, pues, dos modalidades: la fundamentación de la validez de una norma general y la justificación de la pertinencia de la aplicación de una norma general a un caso particular. El principio de universabilidad, característico en el ámbito de la fundamentación o justificación de normas, halla su equivalente en el principio de adecuación cuando pasamos al terreno de la aplicación de normas. El juicio de aplicación es el producto de una argumentación dirigida por una exigencia de imparcialidad. Esta exigencia se traduce en el principio procesal según el cual no se puede establecer que una norma pueda aplicarse legítimamente en una situación sin que se tomen antes en consideración todas las características de la situación que son relevantes para garantizar una interpretación coherente de todas las normas aplicables. Tal criterio de validez se impone tanto en el juicio moral como en el juicio jurídico. Sin embargo, los teóricos de la argumentación jurídica habían pasado por alto, en general, esta elemental distinción, tan pertinente para la comprensión del discurso jurídico. Pues, éste se refiere no tanto a la fundamentación de normas, sino a la aplicación imparcial de normas que se consideran válidas -aunque entonces habría que precisar que no se trata del discurso jurídico en general, que también abarca la tarea legislativa, sino tan sólo del discurso judicial encargado de poner en práctica las normas ya establecidas-. Una norma jurídica particular es correcta sólo si se apoya en normas válidas y en su aplicación adecuada. De este modo la norma aplicada aparece como la utilización óptima de un sistema de normas válidas -es decir, ya fundamentadas en un proceso discursivo en el que han participado todos los posibles afectados- habida cuenta de todas las circunstancias del caso. Toda norma permanece remitida así a quedar coherentemente complementa da por todas las demás normas válidas del sistema.

Francfort, diciembre de 1993

${ }^{6}$ Versión original: Klaus Günther, «Ein normativer Begriff der Kohärenz für eine Theorie der juristischen Argumentation», en Rechstheorie, n. ${ }^{\circ} 20$ (1989), págs. 163-190. 


\section{KLAUS G $\ddot{U} N T H E R:$}

\section{Un concepto normativo de coherencia para una teoría de la argumentación jurídica*}

Desde que Rawls introdujo el modelo del «equilibrio reflexivo» (reflective equilibrium) en la teoría moral y Dworkin el método de la construcción de una «soundest theory of law» en la teoría del derecho, el principio de coherencia juega un papel de importancia creciente ${ }^{1}$. La variedad de posibles modos de empleo se corresponde con la variedad de significados del predicado «coherente». Parece que sólo se está de acuerdo en que la «coherencia» es más amplia que el principio de no contradicción o consistencia.

Todas las teorías de la coherencia se refieren a la relación entre juicios morales particulares y principios. Su propiedad como procedimiento de validación y como método constructivo consigue que confrontemos estos principios con nuestros juicios admitidos intuitivamente. Si las dos clases de enunciados normativos no concuerdan entre sí, revisamos y modificamos los principios a la luz de los juicios intuitivos y los juicios a la luz de los principios, hasta que hayamos alcanzado el estado de «equilibrio» entre nuestros juicios y principios. El contenido y extensión de estas relaciones de apoyo mutuo pueden hacer las veces de criterio de corrección de nuestros principios y juicios. Si se puede sistematizar un determinado conjunto de principios con estos procedimientos, que conforman una «ética», entonces el equilibrio reflexivo puede valer como «procedimiento de decisión para la

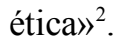

* Versión ampliada y revisada de una conferencia pronunciada por el autor en el Simposio «The Legitimacy of Law» celebrado en el Murikka-Institut. Agradezco a Robert Alexy, a Georg Henrik von Wright y a Jerzy Wroblewski sus enriquecedoras contribuciones críticas a la discusión.

${ }^{1}$ John Rawls: Teoría de la justicia, Fondo de Cultura Económica, México, 1979, pág. 35 y ss.; Ronald Dworkin: Los derechos en serio, Ariel, Barcelona, 1984, págs. 146 y ss., págs. 276 y ss.; Neil MacCornick: Legal Reasoning and Legal Theory, Oxford, 1978, págs. 152 y ss.; id.: «La "tesis de los derechos" en serio», en id.: Derecho legal y socialdemocracia, Tecnos, Madrid, 1990, págs. 109-128; id.: «Coherence in Legal Justification», en Theorie der Normen (FS Weinberger), Berlín, 1984 y s.; Joel Feinberg: Justice, Fairness and Rationality», en The Yale Law Journal, n. ${ }^{\circ} 81$ (1972), págs. 1004 y ss.; Aulius Aarnio: Lo Racional como Razonable, Centro de Estudios Constitucionales, Madrid, 1991; Aleksander Peczenik: Grundlagen derjuristischen Argumentation, Wien/New York, 1983 , págs. 170 y ss.

${ }^{2}$ John Rawls: «Esbozo de un procedimiento de decisión para la ética» en id.: Ética como equidad, Tecnos, Madrid, 1986, págs. 1-17. 
El paralelismo con la teoría de la ciencia es evidente y ha sido ya señalado por los autores $^{3}$. Análogamente al modo en que confirmamos un sistema de enunciados teóricos a través de datos y lo modificamos en caso de encontrar datos que lo contradigan, aprovechamos los juicios morales para confirmar los principios. Ahí logra la «uniformidad» de la teoría («coherent view») una fuerza justificadora ${ }^{4}$. Esta misma llamativa proximidad con el pensamiento sistémico explica la atracción que el principio de coherencia ejerce sobre la teoría del derecho ${ }^{5}$.

Se han formulado múltiples objeciones contra la capacidad del principio de coherencia para justificar principios. Una de ellas sostiene que, al menos, es preciso aclarar cómo la «coherencia» considerada en sí misma basta para justificar enunciados normativos en un sentido específicamente moral. Coherencia es mucho más que una exigencia de racionalidad que dirigimos a las teorías de cualquier clase ${ }^{6}$. Esto guarda también relación con el peligro de un «teoricismo» en la ética, sobre el que Tugendhat ha llamado la atención. La concepción de un procedimiento de decisión según el modelo de construcción de las teorías plantea desde que perspectiva argumenta el constructor de la teoría: ¿reconstruye los principios compatibles con los juicios morales particulares desde la perspectiva de la primera y segunda persona, o argumenta sobre otro «objeto» como si desde la perspectiva de tercera persona aplicara, por ejemplo, sentimientos morales como datos lingüísticos para la construcción de una teoría empírica del sentido de la justicia? ${ }^{7}$ Finalmente no resulta claro si la justificación a través de una interpretación coherente de nuestros juicios particulares y principios no estribaría en una relación circular entre estos dos componentes. Si los juicios particulares deben hacer las veces de «confirmación» de los principios fundamentadores, entonces a través de los juicios particulares no ha de justificarse otra cosa distinta de lo que ya desde siempre se había considerado justificado por los juicios particulares. Estos, empero, pueden fundamentarse en prejuicios, distorsiones y otras cosas por el estilo. Por eso Rawls debe apoyar los requisitos complejos en los

${ }^{3}$ Rawls (nota 1), pág. 38; Ernst Tugendhat: «Observaciones sobre aspectos metodológicos de Una teoría de la justicia de Rawls», en id.: Problemas de la ética, Crítica, Barcelona, 1988, págs. 15 y ss. (pág. 17).

${ }^{4}$ Rawls (nota 1), pág. 39.

${ }^{5}$ Robert Alexy / Aleksander Peczenik: «The Concept of Coherence and Its Significance for Discursive Rationality», comunicación al Simposio «The Legitimacy of Law», en el Murikka-Institut de Finlandia, 4-7 agosto de 1988.

${ }^{6}$ Tugendhat (nota 3), pág. 21.

${ }^{7}$ Ibidem, pág. 18. 
«juicios ponderados» con los que pueda cumplir su función justificadora ${ }^{8}$.

A continuación quiero iluminar un aspecto de este modelo defendido, sobre todo, por Feinberg e, indirectamente, también por Dworkin. Argumentan desde el supuesto intuitivamente convincente de que en nuestras reflexiones morales no siempre cuestionamos todos los principios y juicios que usamos. Más bien aceptamos -solos o en común- un conjunto determinado de enunciados normativos como dados. En base a estos enunciados normativos presupuestos como dados es ya posible producir resultados moralmente sustanciosos: la confrontación con los juicios particulares nos compele a solventar las colisiones entre distintos principios, que tomados cada uno por separado consideramos correctos ${ }^{9}$.

Este modelo es productivo en el sentido de que amplía nuestro saber sobre el conjunto de juicios intuitivos y principios aceptados por nosotros, es productivo de todas maneras sólo porque los juicios intuitivos pueden contener elementos de sorpresa y de inesperabilidad. Éste es siempre, pues, el caso cuando nos encontramos en una situación inédita e inhabitual en la que con nuestras orientaciones tradicionales no nos arreglamos como hasta ahora. A tales situaciones llegamos no sólo con nuestras orientaciones teóricas, sino también con las morales. Tales situaciones pueden entrañar características que sólo podemos tomar en consideración bajo el precio de cambiar el conjunto de nuestros principios o incluso nuestra «ética» (esto es, la teoría moral que ordena sistemáticamente nuestros principios). A menudo emitimos un juicio intuitivo en referencia a una situación concreta. El conjunto imprevisible de posibles situaciones y sus correspondientes diferentes constelaciones características cambian continuamente la significación de los principios sobre los que apoyamos nuestras reflexiones morales intuitivas. Por esta razón experimentamos que el juicio moral particular que consideramos correcto en una situación no resulta compatible a primera vista con principios que en otras circunstancias aceptaríamos como válidos.

Desde luego esto es aplicable sobre todo a los casos tales en los que la confrontación con un nuevo caso fuerza la revisión recíproca

${ }^{8}$ Rawls (nota 2); Norbert Hoerster: «John Rawls’ Kohärenztheorie der Normenbegründung», en O. Höffe (ed.): Über John Rawls' Theorie der Gerechtigkeit, Francfort, 1977, págs. 57 y ss.; Ernst Tugendhat (nota 3), pág. 23. Para ampliar el concepto de equilibrio reflexivo mediante la asunción de teorías empíricas, cfr. Norman Daniels: «Wide Reflective Equilibrium and Theory Acceptance in Ethics», en The Journal of Philosophy, 1979, pág. 256.

${ }^{9}$ Feinberg (nota 1), págs. 1019 y ss.; id.: Harm to Others, Oxford, 1884. Cfr. también el concepto dworkiniano de «Integrity»: Ronald Dworkin: El imperio de la justicia, Gedisa, Barcelona, 1988, págs. 123 y ss. 
de juicios y principios, esto es, en un caso donde emitimos un nuevo juicio. Pero si la novedad del caso producida por la cambiante constelación de situaciones pone siempre de nuevo en movimiento al equilibrio reflexivo, puede especificarse el principio de coherencia en el caso mismo. Con esto se alcanza la «zona realmente productiva».

Si esta consideración es correcta, el principio de coherencia satisface una expectativa que vinculamos a un juicio moral «reflexivo», sin que esto, desde luego, quedase de manifiesto en los modelos propuestos hasta ahora. Esta expectativa conduce a la «adecuación» de un juicio moral en la situación concreta, en la que emitimos este juicio o a la que lo referimos. Cuantos más rasgos de la situación se consideran en nuestro juicio intuitivo, tanto más elevada será la verosimilitud que con la adquisición del equilibrio reflexivo hemos considerado todos los aspectos moralmente relevantes del caso particular. Un juicio tal no ha de ser tomado solamente por eso como correcto, porque está apoyado en principios válidos, sino también porque estos principios han sido aplicados adecuadamente a la situación concreta. Por eso nos parece este juicio más adecuado que uno que se ha efectuado a través de la aplicación «rigurosa» de sólo un principio o de sólo algunos.

Si uno reconstruye el principio de coherencia en base a esta experiencia que hacemos en las situaciones de aplicación, se hará patente por qué la teoría de la coherencia puede cumplir sólo de una manera limitada la tarea que tiene asignada de fundamentar la corrección o validez de nuestros juicios y principios morales. Si es correcto que siempre hacemos reflexiones sobre la coherencia tan pronto como en situaciones cambiantes contamos con posibles nuevos significados de nuestros principios, la corrección de nuestros juicios depende de la medida en que nuestros juicios intuitivos consideren diferentes rasgos de la situación, y con eso cambia el contenido de los principios tomados por correctos y, por tanto, el estado del equilibrio reflexivo. Si esto es así, entonces en el marco del modelo de la coherencia ya no puede contestarse a la cuestión de cuándo podemos considerar como correctos los principios independientemente de las posibles situaciones de aplicación.

A continuación quiero aclarar la propuesta de que los argumentos de coherencia son esenciales sobre todo para la aplicación imparcial de normas. Para este fin introduciré y justificaré por medio de la ética discursiva la diferenciación entre fundamentación y aplicación de las normas (I). A continuación explicitaré el principio de la interpretación coherente como aquel principio con el que podemos justificar en los discursos de aplicación la pretensión de una aplicación adecuada de una norma válida (II). El modo de empleo del principio de coherencia, reconstruido desde la perspectiva de un participante en una argumentación moral, lo aplicaré finalmente a la argumenta- 
ción jurídica (III). Ahí se mostrará que la teoría propuesta por Alexy de la argumentación jurídica como caso especial del discurso práctico general debe ser revisada. Defenderé la tesis de que la argumentación jurídica es un caso especial del discurso moral de aplicación, en el que se trata la adecuación de la aplicación de normas.

\section{El ideal de una norma perfecta}

Una fundamentación discursiva de normas válidas debe asegurar que una norma exprese un interés general en su seguimiento general. Este interés general procede de la consideración recíproca de los intereses de cada uno. La reciprocidad de la consideración de intereses es proporcional a la fuerza de convicción de las razones que se introducen para un seguimiento general de la norma. Una norma estará pues fundamentada si cada individuo puede aprobarla con razones. Para que realmente sólo la fuerza de las razones y ningún otro motivo logre validez, se tiene que poder suponer que se cumplen determinadas condiciones idealizadas de la argumentación. A estas condiciones pertenecen, aparte de las reglas de consistencia semántica y lógica que valen para todos los tipos de fundamentaciones, así como ciertas reglas para ordenar las contribuciones de los interlocutores, la posibilidad de participación libre e igual de todos los afectados. Sólo bajo este presupuesto mencionado anteriormente ha de esperarse un consenso motivado racionalmente de modo no coactivo. Por medio de esta condición se asegura la reciprocidad universal de la validez de la norma ${ }^{10}$.

Forma parte de estas condiciones ideales que los participantes puedan disponer de un saber ilimitado y de un tiempo infinito ${ }^{11}$. Con estos presupuestos los participantes en el discurso deben poder prever las consecuencias y efectos laterales de un seguimiento general de la norma por cada cual en una posible situación de aplicación. El saber no estará limitado a algunos tipos de situaciones que podamos dominar en el momento actual, y que podemos utilizar de modo ilustrativo en el discurso para mostrar cuáles serán las consecuencias y efectos secundarios que probablemente van a surgir en caso de un seguimiento general de la norma. Más bien debe hacerse presente toda posible situación de aplicación con todos sus posibles rasgos, esto es, una descripción completa. Sólo si se puede suponer que esta

${ }^{10}$ Jürgen Habermas: «Ética del discurso. Notas sobre un programa de fundamentación», en Conciencia moral y acción comunicativa, Península, Barcelona, 1985, págs. 57-134.

${ }^{11}$ Klaus Günther: Der Sinn für Angemessenheit. Anwendungsdiskurse in Moral und Recht, Francfort, 1988, págs. 37 y ss. 
condición se cumple, se encuentra cada participante individual en la situación de juzgar en cada situación particular los efectos de un seguimiento general de la norma para sus intereses particulares. No habría tampoco, pues, una «situación de aplicación» que fuera diferente de estas situaciones a las que se refiere un participante en un discurso de fundamentación de una pretensión de validez; ambas magnitudes son coextensivas. Una norma fundamentada de tal manera sería «perfect». Podría regular su propia aplicación, porque todas sus posibles aplicaciones individuales habrían sido tema del discurso y la adecuación de su aplicación pertenecería al significado de su validez. Cualquier situación individual, en la que el interés de un individuo pudiera verse afectado por el seguimiento general de una norma concreta, habría sido ya considerada en el discurso de fundamentación. Los participantes en el discurso tendrían la certeza de que no habría ninguna situación en la que el seguimiento de la norma lesionara un interés generalizable.

El ideal de una norma «perfecta» sale al encuentro de nuestras intuiciones morales, pero resulta problemático por diferentes razones. Por un lado es abiertamente irrealista la hipótesis de que los participantes en un discurso puedan encontrarse alguna vez en la situación de poder disponer de un saber ilimitado y de un tiempo infinito. A pesar de todo podría tratarse de un requisito supuesto que sólo es satisfecho de modo contrafáctico. Pues las hipótesis de un saber ilimitado y un tiempo infinito, del mismo modo que las restantes condiciones idealizadas de argumentación, formarían parte de los requisitos pragmáticos de una argumentación sobre la pretensión de validez de una norma. Pero parece cuestionable -y aquí se encuentra el otro problema conceptual- que esta vinculación sea necesaria. Deseo defender la tesis de que con la fundamentación imparcial de la validez de una norma pensamos algo diferente a su aplicación imparcial en un caso particular. Debería señalarse que a nuestra comprensión pragmática de una norma válida no pertenece la adecuación de su aplicación en cualquier caso particular, por lo que tampoco sería necesaria aquella hipótesis irrealista de que debamos estar en la situación de prever todas las colisiones pensables de intereses en todos los posibles casos particulares. Para la adecuación de la aplicación de una norma válida habría que reflexionar si se puede destacar de otra manera el aspecto de razón práctica.

\section{I.1. Colisiones internas y externas de normas}

Que no nos refiramos a todas las situaciones particulares de aplicación cuando reconocemos una norma como «válida» resulta ya 
claro en nuestro uso coloquial de este predicado. Lo adjudicamos también a normas tales que sabemos que pueden colisionar en algunas situaciones con otros intereses generalizables. Así sabemos, por ejemplo (y podríamos también prever esto sin más en un discurso sobre la validez de normas afectadas), que la norma «las promesas han de mantenerse», en algunas situaciones colisiona con la norma «ayuda a tu prójimo, si se encuentra en una situación de necesidad». Éste sería siempre el caso cuando en razón de circunstancias especiales solamente puedo cumplir o una norma o la otra, pero no ambas a la vez. Los intereses incorporados en ambas normas son generalizables sin problemas. A pesar de que su colisión resulte muy probable, mantenemos ambos preceptos no como inválidos; por el contrario, encontraríamos curioso que un discurso sobre la validez de una de las dos normas se dirigiese al resultado opuesto a causa de esta posibilidad de colisión.

Diferente es si nos preguntamos por la validez de una norma como, por ejemplo, «siempre que te proporcione una ventaja, está permitido no mantener una promesa». Aquí podríamos prever igualmente sin dificultades que los efectos de un seguimiento general de la norma lesionan un interés generalizable, por ejemplo, el interés de aquellos que confían en el mantenimiento de una promesa. A diferencia del primer caso aceptaríamos esta colisión de normas ahora empero como un argumento contra la universabilidad y, por eso, contra la validez de la norma. Aunque en ambos casos las previsibles consecuencias y efectos laterales de un seguimiento de normas colisionan con los intereses generalizables de otros, sacamos otra consecuencia en cada caso: en el primer caso consideramos la norma como válida a pesar de la colisión, en el segundo caso no.

La razón de este tratamiento diferenciado de casos de colisiones previsibles es evidente. En el primer caso colisionan entre sí dos normas generalizables, en el segundo caso es patente que sólo una de las dos normas que colisionan entre sí es generalizable. Esta diferencia sugiere la sospecha de que la primera clase de colisión no es relevante para argumentar sobre la validez de una norma, sino sólo la segunda. Desde la teoría del discurso puede explicarse esta diferencia indicando que en ambos casos las previsibles colisiones de intereses en la aplicación de normas juegan respectivamente papeles diferentes. En el primer caso tiene lugar un cambio de perspectiva bajo la consideración de todas las circunstancias de la situación de aplicación. Los participantes en el discurso se refieren aquí a una situación en la que se encuentran por determinar qué intereses generalizables pueden ser previsiblemente molestados por las consecuencias de la aplicación de una norma. Independientemente de esta situación, en la que el precepto de veracidad colisiona con el deber 
de prestación de auxilio, puede pensarse colisiones con otras normas generalizables. Por supuesto, ninguna de estas anticipaciones -en principio, indefinidas- de posibles casos de colisión nos da una razón para reprobar una norma como inválida.

Por el contrario, en el segundo caso se trata exclusivamente de intereses tales que en cualquier situación se ven afectados en la misma medida. En todas las situaciones en las que se hace uso del permiso de romper una promesa son lesionados los intereses de aquellos que habían confiado en su mantenimiento. Aquí se indica los intereses menoscabados independientemente de las situaciones en las que los participantes en el discurso se encuentran en el momento o pudieran encontrarse en un futuro. Necesitan referirse recíprocamente a aquellos efectos que un seguimiento general de una norma tiene, bajo circunstancias que permanecen iguales, en cualquier situación de aplicación. Si se muestra que ya, bajo circunstancias que permanecen iguales, en cualquier situación se lesiona un interés común, puede que la norma dudosa no sea válida. En este caso sólo se puede generalizar realmente uno de los dos intereses que colisionan entre sí. El cambio de perspectiva fuerza a los participantes en el discurso a tomar una decisión excluyente (Entweder-Oder-Entscheidung). A continuación se hará referencia a esta clase como colisión interna y a la primera, por contra, como externa. Las colisiones internas afectan a la validez de una norma. Por medio de una negación son identificables independientemente de las situaciones reales de aplicación. Por el contrario, las colisiones externas sólo pueden identificarse en situaciones de aplicación ${ }^{12}$.

Si esta aclaración de la relación entre validez normativa y comportamiento colisivo es sólida podemos reconocer no sólo el precepto de prestar ayuda sino también el de veracidad como normas válidas, aunque sepamos que existen situaciones en las que colisionan entre sí. Esta circunstancia no es relevante para la validez. No en toda situación en la que alguien necesita ayuda, hemos de cumplir al mismo tiempo una promesa, y no en toda situación en la que debemos cumplir una promesa, estamos obligados al mismo tiempo a

${ }^{12}$ Esta propuesta de comprobación de la colisión interna se corresponde con la de Albrecht Wellmer de reconstruir la generalización moral de las formas de acción como una doble negación de una máxima. Albrecht Wellmer: Ethik und Dialog, Francfort, 1986, pág. 22. La distinción entre colisiones normativas internas y externas desplaza la distinción de Robert Alexy entre reglas y principios desde la dimensión de la estructura normativa a la de la aplicación: el comportamiento colisivo de reglas vale para todas las normas si se atiende al tipo de colisión interna; el comportamiento colisivo de principios vale para todas las normas si se atiende al tipo de colisión externa. Robert Alexy: Theorie der Grundrechte, Suhrkamp, Francfort, 1986, págs. 71 y ss.; Günther (nota 11), págs. 268 y ss. 
prestar ayuda. Por eso podemos argumentar que también los necesitados de ayuda tienen un interés en que se mantengan las promesas, y viceversa.

\section{I.2. Validez y adecuación de normas}

Aunque las colisiones externas sean irrelevantes para la argumentación sobre la validez de una norma, no se puede concluir sin embargo que moralmente carezcan de significación. Este resultado podría contradecir patentemente nuestras intuiciones morales, sobre todo si no es falsa la presunción de que en situaciones moralmente complejas nos vemos obligados a entendemos más frecuentemente con colisiones de la primera clase ${ }^{13}$. El resultado de un discurso sobre la validez de la norma ya no puede ser que aquellos intereses, que no sean referibles a las circunstancias que en cualquier situación de aplicación permanecen iguales, puedan ser lesionados en caso de colisión. Elijamos como ejemplo la colisión normativa, citada a menudo, que surge cuando alguien (al que llamo "X») ha prometido a su amigo Smith ir a su fiesta y, al poco, se entera de que su amigo Jones está gravemente enfermo y necesita urgentemente ayuda. Esta es una situación del tipo tal que podemos preverla en un discurso sobre la validez de la norma que ordena mantener las promesas. Pero como tampoco concluimos que esta norma sea inválida a causa de la colisión previsible con el precepto de prestación de auxilio, en atención a esta situación concreta podríamos aceptar el argumento de que de la aplicación de la norma válida del precepto de veracidad se deriva en este caso el deber de omitir la prestación de auxilio.

Este argumento sólo sería convincente si no hubiera en ninguna situación de aplicación otras circunstancias que las presupuestas en el discurso de validez. Por otra parte las reglas del discurso de validez, según el requisito anteriormente aclarado, no ordenan referirse en la fundamentación a estas otras circunstancias que en cada caso de aplicación son diferentes. Dado que la validez sólo depende de que un seguimiento general de la norma bajo las mismas circunstancias sea de nuestro interés común, entonces basta con limitar a estas circunstancias las descripciones de la situación empleadas. La descripción de la situación no debe ser en absoluto completa en cuanto a las circunstancias variables.

$\mathrm{Si}$ en la aplicación de normas nos apoyamos en esta descripción selectiva de situaciones, llegamos a resultados que contradicen

\footnotetext{
${ }^{13}$ Sobre el concepto de «situación moralmente compleja», cfr. Wellmer (nota 12), págs. 127
} y ss. 
claramente nuestras convicciones morales. Al limitarse ahora $\mathrm{X}$ al precepto de mantener las promesas como razón para aducir la prestación de auxilio omitida, habría efectuado un recorte en la situación que en un discurso de validez podría presuponerse: que había dado una promesa a alguien que confiaba en su mantenimiento. El interés asimismo generalizable de su amigo Jones a la prestación de auxilio sería, pues, relevante si hubiera una obligación de moral de considerar todos los rasgos de una situación de aplicación. Es claro que de la idea de imparcialidad se sigue una obligación tal. No es claro cómo puede fundamentarse sin recurrir al ideal de una norma perfecta.

Si delimitamos el concepto de validez a la reciprocidad de la consideración de intereses bajo condiciones que se mantienen iguales, este concepto ya no implica la adecuación de la aplicación de una norma bajo cualquier circunstancia. De cara a una situación de acción las normas válidas sólo son aplicables prima facie. Éste es siempre el caso si las circunstancias previstas por ellas se dan en una situación de aplicación. Las circunstancias que se mantienen iguales deben completarse, por tanto, con una descripción íntegra de la situación que considere también las circunstancias variables en cada situación. Dado que esta tarea no la puede atender ex definitione un discurso de validez, se necesita para ello un discurso de un tipo especial, al que en lo sucesivo me referiré como «discurso de aplicación». Tan pronto como iniciamos este discurso debemos ampliar la perspectiva presupuesta con la validez de una norma a las circunstancias que se mantienen en cada situación. En el discurso de aplicación las normas válidas tienen tan sólo el status de razones prima facie para la justificación de enunciados normativos particulares tipo «debes hacer ahora p». Los participantes saben qué razones son las definitivas tan sólo después de que hayan aducido todas las razones prima facie relevantes en base a una descripción completa de la situación. A la luz de este principio gana la objeción de que Jones se encuentra en una situación de desamparo y, por eso, el precepto de prestación de auxilio ha de considerarse con el status de un argumento. Este argumento apunta no ya a la validez de las normas en colisión, sino a su adecuación bajo la consideración de todas las circunstancias de la situación.

Por esta vía alcanzamos indirectamente el ideal de una norma perfecta: analizando en dos pasos la exigencia de considerar todas las circunstancias de cada situación de aplicación particular. No anticipamos en un momento dado todas las circunstancias de cada situación de aplicación particular, sino que en cada situación de aplicación correspondiente anticipamos en un momento determinado todas las circunstancias. Con esto se resuelve el problema de que reconocemos algunas normas como válidas a pesar de saber que en algunas 
situaciones colisionan con otras normas válidas. Si uno delimita el concepto de validez a las circunstancias presupuestas por las normas como inalteradas, se torna comprensible que en los casos de colisión más interesantes no se trata de la validez sino de la adecuación de una norma aplicable prima facie. El ideal de una norma perfecta sub sume por error el concepto de adecuación en aquel otro de validez. Esta diferenciación conceptual entre validez y adecuación tiene aquel efecto lateral buscado de poder renunciar en el discurso de validez a los requisitos irrealistas de saber ilimitado y tiempo infinito. Las consecuencias y efectos laterales que se derivan de un seguimiento general de la norma bajo circunstancias que permanecen iguales pueden determinarse casi siempre en base del saber disponible en un espacio de tiempo limitado.

\section{I.3. La aplicabilidad prima facie de normas válidas}

Al concluir este apartado quiero discutir brevemente unas objeciones que pueden dirigirse contra esta propuesta de reconstrucción: la primera se refiere a la obligatoriedad o «normatividad» prima facie de las normas aplicables (a); la segunda a la presunta superfluidad del discurso de aplicación (b); y la tercera al peligro de una relación circular entre fundamentación y aplicación (c).

a) Que las normas de acción sólo sean aplicables prima facie no significa que la razón práctica se suspenda en la aplicación. Si nos orientamos por el ideal de la norma perfecta, se muestra que el carácter prima facie contiene un sentido racional. Los participantes de un discurso de aplicación están obligados a considerar una norma aplicable prima facie como razón para la fundamentación de un juicio particular. La reserva prima facie significa meramente que para una justificación de un juicio particular no basta con invocar que es aplicable una norma válida. Quien aduce una razón tal debe poder mostrar en caso de duda que es compatible con todas las demás normas aplicables prima facie en dicha situación. Con esta reserva prima facie se impone a los participantes en el discurso una carga de argumentación recíproca, en virtud de la cual se obligan a fundamentar la restricción o suspensión de una razón válida que era aplicable en una descripción completa de la situación ${ }^{14}$.

${ }^{14}$ Searle desarrolla con el concepto de implicador conversacional una obligación análoga. Cfr. John Searle: «Prima Facie Obligations», en J. Raz (ed.): Practical Reasoning, Oxford, 1978, págs. 81 y ss. 
b) Otra objeción expresa que una diferenciación entre validez y adecuación es superflua porque podríamos referirnos en un discurso de fundamentación directamente a la situación en la que nos encontramos cada vez. Pues todas las circunstancias que pertenecen a una descripción completa de la situación de aplicación figuran entre las circunstancias que permanecen iguales de aquella norma que alguien propone en dicha situación. Esta objeción conduciría a una mera inversión del problemático ideal de «norma perfecta». La validez de una norma se agotaría en su adecuación. En lugar de una norma perfecta, que sería en cualquier situación de aplicación no sólo válida, sino también aplicable definitivamente, tendríamos tan sólo normas ad hoc que son válidas en una situación única. Esta inversión del ideal de norma perfecta tendría la desventaja de que estaríamos confrontados en cada situación de nuevo con una tabula rasa moral, porque no podríamos más presuponer ninguna norma válida como razones aplicables prima facie. Esta desventaja se suprime si uno parte de que en cada situación hay varias normas válidas aplicables prima facie, pero sólo una norma adecuada.

En contra de la primera apariencia, la aplicabilidad prima facie de las normas válidas no implica tampoco que las normas válidas carezcan de significado moral y que el discurso de validez sea un procedimiento de comprobación superfluo. Aun cuando podamos encontrar sólo en el discurso de aplicación la razón definitiva, no podemos renunciar al procedimiento de supervisión de la validez de las razones normativas. Como se ha indicado anteriormente, examinamos en un discurso de validez si una norma propuesta es realmente de nuestro interés común. Lo que no podemos querer bajo circunstancias que permanecen iguales contradice nuestro interés racional. En atención al discurso de aplicación se formula: lo que entra en contradicción con nuestro interés racional no debería tampoco emplearse como razón prima facie en un discurso de aplicación.

c) Contra esta propuesta podría objetarse, en tercer lugar, que la diferencia entre validez y adecuación sólo es posible pagando el precio de un círculo vicioso. También en los discursos de fundamentación deberíamos aplicar, al menos hipotéticamente, las normas a las situaciones, para poder imaginamos su contenido proposicional. Es cuestionable si en esa aplicación hipotética no deberíamos hacer aquellas interpretaciones que habíamos dejado reservadas para el discurso de aplicación. Convenientemente, la concepción aquí propuesta del discurso de aplicación habría de examinar si la constatación de la aplicabilidad prima facie de la norma válida en una situación, presupuesta ya al menos implícitamente en aquellas interpretaciones, no debe hacerse explícita en los discursos de aplicación. 
También los participantes en un discurso de fundamentación deben saber lo que significa seguir una regla. Para la aplicación hipotética basta con que los participantes estén de acuerdo en emplear las expresiones normativas con el mismo significado. Debe ser el mismo contenido proposicional sobre el que argumentamos en un discurso de fundamentación. Por el contrario, no depende de que las situaciones de aplicación planteadas hipotéticamente se hayan descrito de un modo completo para considerar todos los casos de colisión. El empleo con igual significado de las expresiones normativas es, más bien, una condición mínima para poder alcanzar el objetivo que define el discurso de fundamentación: los participantes generalmente quieren descubrir si una norma en litigio corresponde a su interés general. De una norma tal podemos decir o bien que definitivamente no es válida, o bien que es aplicable prima facie.

A pesar de todo podría hacerse la pregunta inversa, esto es, si al iniciar un discurso de aplicación no deberíamos «aplicar» una norma válida para poder decidir en principio si pertenece a la clase de normas aplicables prima facie. Para poder decir en principio que una norma válida es aplicable prima facie en una situación «S» deberíamos haber ya realizado al menos ya implícitamente una aplicación. Esta aplicación realizada no convierte de ningún modo en superfluo el discurso de aplicación. Si aquella interpretación o regla semántica sobre la que apoyamos nuestra aplicación prima facie puede justificarse también en relación a una descripción completa de la situación, sólo puede resolverse en un discurso de aplicación. El discurso de aplicación es la forma reflexiva de esta aplicación prima facie.

Hasta ahora sólo he mostrado que entre la fundamentación de una norma válida y su aplicación adecuada existe una diferencia desde el punto de vista de la teoría del discurso. Queda por supuesto pendiente cuáles son los criterios desde los que juzgamos la imparcialidad de una aplicación normativa y qué clase de argumentos empleamos ahí.

\section{El ideal de un sistema coherente de normas válidas}

En los discursos de aplicación se presupone que las normas que empleamos como razones prima facie para la justificación de un juicio particular son consideradas válidas. Los participantes de un discurso de aplicación comparten de antemano un conjunto determinado de razones normativas válidas. Están ya seguros de su reconocibilidad y están de acuerdo con lo que quieren o no quieren desde el punto de vista racional bajo la consideración de circunstancias que permanecen iguales. Al disponer del mismo sistema de reglas válidas, examinan implícitamente qué razones deben ser presupuestas 
como válidas en un discurso de aplicación $\mathrm{y}$, por tanto, consideradas como normas aplicables prima facie, si se trata de la justificación de un juicio moral particular. Ninguna otra cosa significa que normas y principios «estén dados de antemano», de donde también procede el modelo de la coherencia.

En el discurso de aplicación cambia el punto de vista desde el que se tematiza una norma. En vez de enjuiciar su validez, ahora se aprecia su referencia a la situación. Puede determinarse qué norma es adecuada en una situación si los participantes se han referido a todas las normas aplicables prima facie a una descripción completa. Ahí es inútil preguntarse si los participantes en el discurso disponen primero de una descripción completa de la situación y luego de todas las normas aplicables prima facie o si la descripción de la situación sólo se muestra «a la luz» de una precomprensión de las posibles normas aplicables. El problema del círculo hermenéutico puede permanecer abierto. Los participantes sólo saben con que normas puede colisionar una norma aplicable prima facie en una situación de aplicación si han señalado en las normas aplicables todos los rasgos relevantes de una descripción de la situación.

\section{II.1. Actuación selectiva}

El proponente de una norma aplicable prima facie no defiende pues la validez, sino la adecuación de la aplicación de una norma sobre la que se apoya un juicio particular. El oponente no duda de la reconocibilidad de la razón normativa misma, sino de su fuerza en apoyo de un juicio particular. En nuestro ejemplo, la validez del deber de veracidad no lo discute ningún participante. Pero no es claro que el juicio particular «X debe ir a la fiesta de Smith» pueda ser justificado en esta situación adecuadamente a través de aquella norma. No debe uno equivocarse con la importancia de este problema por una descripción demasiado sencilla. El juicio particular «tú debes hacer p (aquí y ahora)» no se apoya sin problemas en la norma «en la situación $\mathrm{S}$ se debe hacer $\mathrm{X}$ » $\mathrm{y}$ en la constatación «se da $\mathrm{S}$ ». Pero ya el traslado de este esquema a nuestro sencillo ejemplo explica que dudásemos si el deber de veracidad había sido aplicado adecuadamente cuando extraíamos en esta situación la conclusión de que «X debe ir a la fiesta de Smith».

El sencillo esquema es claro sólo porque supone la igualdad de significado de la expresión «S», tal como se empleará en la norma y en la descripción de la situación. Esta igualdad de significado no existe desde un principio, más bien es el resultado de un precedente en el que «aplicamos» la norma y con ello al mismo tiempo destaca- 
mos determinados rasgos de la situación como «relevantes» frente a otros. Esta actuación selectiva puede criticarse de todas maneras. Un oponente podría preguntar: «¿Por qué te refieres sólo a estas circunstancias de la situación y no a otras?». En nuestro ejemplo Jones podría dirigir a X la pregunta, por qué considera sólo relevante el aspecto de la situación de que ha prometido a Smith ir a su fiesta y no que su amigo se encuentra en una situación desamparada. Esta pregunta no puede responderse con una referencia al deber de veracidad. Tampoco es suficiente si $\mathrm{X}$ explica su comprensión del significado del deber de veracidad remitiéndose a que el modo de la palabra dada a Smith puede caracterizarse como una promesa y esta interpretación puede justificarse también con razones. Esta respuesta tan escasamente suficiente sería la prueba de que la norma «se debe mantener las promesas» puede ser fundamentada por principios o en un discurso de validez. Este modo de justificación presupone una descripción de la situación ya seleccionada. No hay ningún tránsito de esta norma a la otra norma aplicable prima facie que obliga a prestar ayuda. Tan sólo obtenemos una visión de las normas que colisionan unas con otras en una situación de aplicación si tematizamos las características selectivas de nuestra comprensión normativa y no las presuponemos sencillamente. Para que una interpretación normativa pueda ser tematizada como una actuación selectiva se precisa una descripción completa de la situación.

\section{II.2. Regla de selección y regla de uso de las palabras}

De ahí que debamos seguir el principio de considerar en la aplicación de una norma todos los rasgos de la situación, incluso en la interpretación normativa misma. En contra se podría objetar que la estipulación de un significado a través de la interpretación normativa

y de la selección de los rasgos de la situación son dos cosas distintas. Puede examinarse independientemente de la situación si hablante y oyente comprenden correctamente una norma. Si bien las reglas de empleo de los términos pertenecientes a una norma son simultáneamente también reglas de selección de la aplicación de la norma a una situación, juzgamos ambos tipos de reglas con diferentes criterios. Puede replicarse a esta objeción que el principio de considerar en la interpretación normativa todos los rasgos de la situación, de ningún modo implica una teoría de la constitución del significado con independencia de la situación. Se exige meramente que el establecimiento de una regla de uso de las palabras deba considerar en una interpretación coherente todas las colisiones externas con las otras normas aplicables prima facie. Esta exigencia se cumple si el carácter 
de la regla de uso de las palabras puede ser tematizada como una regla de selección, porque de otro modo las normas que colisionan externamente no son identificables como normas aplicables prima facie. La tematización de una regla de uso de las palabras como regla de selección presupone por eso una descripción completa de la situación.

La cuestión de qué interpretación concuerda con la descripción de la situación y cómo ha de ser justificada, no puede separarse de la consideración de las otras normas aplicables prima facie. Tampoco lo hacemos de un modo manifiesto cuando un oponente objeta por qué consideramos esta circunstancia y no aquélla otra y respondemos que las otras circunstancias «no son relevantes». Pues la consideración de las otras normas ha pasado ya a formar parte de nuestra interpretación. En la teoría hermenéutica esto se designa como «precomprensión» y en la teoría de la ciencia como «contexto de descubrimiento». Mi tesis es que con el concepto de adecuación aquí desarrollado se puede reconstruir racionalmente al menos un aspecto de este problema: la selectividad de la interpretación requiere de justificación y tiene también capacidad justificatoria en los discursos de aplicación.

\section{II.3. Interpretaciones coherentes}

¿Cómo podemos lograr referirnos en la aplicación normativa al mismo tiempo a todas las normas aplicables en una situación? Vuelvo de nuevo a nuestro ejemplo estándar. Para el juicio particular

(N1) Se debe ayudar a mi amigo Jones

pueden imaginarse diferentes justificaciones, de las cuales sólo una cumple el criterio de la adecuación. Sería pensable justificar este juicio particular a través de una referencia a la norma

(NI) Se debe ayudar a un amigo que se encuentra en caso de necesidad.

Esto se corresponde con el sencillo esquema anteriormente citado: que de la norma «se debe hacer $\mathrm{p}$ en S» junto con la constatación «que S» se deriva el juicio particular «se debe hacer $\mathrm{p}$ aquí y ahora». La justificación del juicio particular se apoya en una norma válida, cuya reconocibilidad general nadie va a poner en duda seriamente. Pero para encontrar si el juicio particular se basa también en una aplicación adecuada de una norma, la justificación debe ser más 
compleja. Como la norma válida (NI) sólo es aplicable prima facie, y un oponente podría por tanto preguntar por qué el proponente no sigue la otra norma igualmente aplicable prima facie en la situación dada:

(NII) Se debe mantener las promesas.

Dado que estamos obligados por la reserva prima facie a examinar todos los rasgos de la situación, también debe introducirse esta norma aplicable prima facie en el discurso de aplicación. Ella es válida tomada en sí misma y podría ser lesionada en la situación dada si la norma (NI) fuera seguida. El proponente que quiere defender la adecuación de la aplicación de (NI) ha de asumir ahora la carga de la argumentación. Pues como no puede declarar la norma (NII) como inválida, no le cabe otra cosa que mostrar bajo qué condiciones las normas (NI) y (NII) que colisionan entre sí en esta situación son compatibles entre sí. En este nivel comienza la interpretación coherente de las normas aplicables en una descripción completa de la situación. En nuestro simple ejemplo no es difícil anticipar el resultado de esta interpretación. El resultado podría ser:

(NIII) Para ayudar a alguien que de repente se encuentra en un caso de extrema necesidad, no debe mantenerse una promesa insignificante.

En nuestro ejemplo, la norma (NIII) sería la única justificación adecuada del enunciado normativo particular (N1): se debe ayudar a Jones. ¿Cómo se puede fundamentar este iluminador resultado intuitivo a través de una interpretación coherente?

Para responder a esta pregunta recurro a la ayuda de otra intuición. En vistas del resultado obtenido en el sencillo mundo de nuestro ejemplo, se está próximo a decir que sobre el precepto de mantener las promesas apenas se podría pensar nada diferente a que en las situaciones como las propuestas se le pudiera conceder prioridad sobre el deber de prestación de auxilio. Desde luego, contamos raramente con esta certeza en las situaciones moralmente complejas.

Para solucionar este problema se ha propuesto por distintos autores que las normas o intereses que colisionan han de ser «ponderados» unos con otros ${ }^{15}$. Tratamos todas estas propuestas, claro está,

${ }^{15}$ R.M. Hare: Moral Thinking, Oxford, 1981, págs. 117 y ss.; Günther Patzig: «El imperativo categórico en la discusión de la ética actual», en idem: Hechos, normas y proposiciones, Alfa, Barcelona/Caracas, 1986, Stuttgart, 1980, págs. 160 y ss.; y Robert Alexy (nota 12), págs. 125 y ss.; MacCormick (nota 1), págs, 129 y ss. 
con la premisa de que normas y principios significan lo mismo que valores y bienes, o que por lo menos se pueden traducir por ellas. Sólo valores o bienes pueden ser medidos cuando menos en un sentido metafórico, de tal modo que es posible una «ponderación» y con ella una decisión en beneficio de uno de los valores que colisionan con los otros. En el presente contexto no resulta posible discutir con la atención debida estas posiciones. Me gustaría sólo cuestionar por qué debe abandonarse por esta razón la distinción entre enunciados normativos y evaluativos.

No aceptada esta alternativa, sólo se ofrece la siguiente salida: si X acepta no sólo el deber de veracidad sino también la obligación de prestación de auxilio, debería pues poder mostrar en el caso de nuestro ejemplo con ayuda de qué otros principios ambos preceptos podrían ser tan compatibles entre sí que el juicio particular «hay que prestar auxilio a Jones» pudiera ser justificado como aquella norma que es adecuada a la situación. La prioridad que adquiere en este caso la obligación de prestación de auxilio sobre el deber de veracidad no vale como expresión de decisión de preferencias o como el resultado de una ponderación de bienes, sino como el resultado de la mejor teoría de todos los principios aplicables ${ }^{16}$. Esta teoría debería explicitar detalladamente el significado de estos principios. La norma que ofrece aquella relación de prioridad no debería aparecer como la realización óptima de los fines que concurren en referencia a todas las posibilidades, sino como el agotamiento óptimo del sentido normativo de ambos principios bajo la consideración de todas las circunstancias.

Contra este modelo puede hacerse dos objeciones: a) la interpretación coherente de las normas que colisionan entre sí parece ser sólo un problema de autoconsistencia del sujeto que actúa moralmente, para cuya solución no se requiere ningún discurso; y b) una interpretación coherente como reconstrucción de un orden transitivo entre diferentes principios parece no ser posible sin la construcción de nuevas normas y tampoco sin la introducción de pretensiones de validez necesitadas de fundamentación, con lo que se pondría en cuestión la distinción hecha anteriormente entre validez y adecuación. Estas objeciones no son, sin embargo, justas.

a) Podría surgir la impresión de como si el modelo de coherencia concibiera la aplicación adecuada de normas como un problema de un actor individual. Esta impresión sólo resulta ajustada a primera vista. Claro que todo actor moral individual siempre se confronta

${ }^{16}$ Cfr. Dworkin (nota 1). Me ocuparé más detalladamente infra de las diferencias con la concepción de Dworkin. 
también consigo mismo, cuando ve que al actuar en una situación de determinada manera que satisface un principio lesiona al mismo tiempo otro. Si X acepta el deber de veracidad así como la obligación de prestación de auxilio, se porta incoherentemente tan pronto como sin pormenorizar razones cumple en nuestro caso la promesa y va a la fiesta de Smith. El principio de ordenar los principios que colisionan entre sí en un caso particular en una teoría uniforme tiene su fundamento moral, aunque no solucione los problemas de consistencia interna de las personas que actúan moralmente. Esto se comprende si ampliamos las perspectivas: en las normas válidas podríamos suponer al menos que serían compartidas por todos los afectados. Porque aceptamos las normas válidas, pero no en referencia a las colisiones externas, no podemos excluir que cualquier individuo en base a normas válidas comúnmente aceptadas llegue a diferentes juicios sobre lo adecuado en la situación «S» ${ }^{17}$. Bajo la presuposición de que los participantes están de acuerdo con las normas aceptadas como válidas que han introducido en el discurso de aplicación como razones prima facie, puede ser justificada la teoría uniforme sólo como resultado de una empresa común de los mismos implicados. Los participantes en un discurso de aplicación se respetan mutuamente como personas que comparten unos con otros principios válidos y normas. Este respeto tan sólo se expresa cuando cada cual considera los principios que colisionan entre sí en una situación en la búsqueda común de una teoría uniforme. En otro caso trataríamos arbitrariamente al participante no considerado que lo tenemos enfrente y aplicaríamos los principios compartidos comúnmente de una manera unilateral y parcial.

b) Otra objeción podría decir que con esta propuesta de solución del problema de las colisiones externas podría ahora allanarse la diferencia entre los discursos de fundamentación y de aplicación. Finalmente es imprescindible para la reconstrucción de una teoría uniforme el hallazgo y construcción de nuevas normas, que no pertenecerían al conjunto de normas válidas comúnmente compartidas. Ninguna reconstrucción es posible sin construcción. Por tanto se debería tener siempre otro nuevo discurso de fundamentación antes de que se pueda aceptar las normas encontradas como elementos legítimos en las múltiples relaciones de apoyo de la teoría uniforme que se construye. Éste no es, sin embargo, tanto el caso en el que se mueve la interpretación en base a, y en los límites del sentido de, las normas comúnmente aceptadas como válidas. En el interior de estos

${ }^{17} \mathrm{Cfr}$. al respecto las experiencias que se relatan en las comisiones de ética, Alasdair MacIntyre: «Does Applied Ethics Rest on a Mistake?», en The Monist (76), 1984, págs. 498 y ss. 
límites perseguimos un sistema coherente ideal entre las normas que colisionan entre sí. Todas las normas construidas de nuevo que sirven al establecimiento de relaciones de apoyo en el interior de este sistema ideal buscado pertenecen al conjunto de normas aceptadas comúnmente como válidas. Un criterio para ello, cuando ya no existe el caso, no puede conducir desde fuera hasta la interpretación coherente. Sólo los implicados mismos podrían juzgar si una nueva norma ya no pertenece a este sistema. Si es polémica la pretensión de validez de esta norma, se podría aclarar en un discurso de fundamentación si la norma encarna un interés general y si debe pertenecer al conjunto de normas aceptadas comúnmente como válidas.

\section{II.4. Paradigmas de interpretaciones coherentes}

De este modo nos hemos acercado reconstructivamente a la idea que está asociada al ideal de una norma perfecta: que su validez y su adecuación serían pues exactamente idénticas si pudiéramos justificar su seguimiento general para cada caso particular de aplicación pensable. Según el procedimiento aquí propuesto deberíamos aplicar una norma como si hubiéramos podido prever la situación de aplicación bajo los requisitos de saber exhaustivo y tiempo ilimitado. Éste es el sentido de la constatación de que una norma es en esta situación la única adecuada. Pero esta pretensión no la podemos satisfacer en un discurso de validez, porque sólo podemos considerar las circunstancias que permanecen iguales en cualquier situación de aplicación. Por otro lado, si no queremos lesionar la idea de imparcialidad en la aplicación de normas no podemos desistir de considerar al mismo tiempo unilateralmente sólo determinados aspectos de la situación sin otra justificación. El desempeño de la pretensión que pertenece a la idea de imparcialidad se desplaza en el eje temporal en el discurso de aplicación. Si mantenemos ahora como válida una norma como NI, aun cuando sabemos que existen algunas situaciones en las que puede colisionar con normas como NII, suponemos contrafácticamente que todas las normas válidas forman finalmente un sistema coherente ideal que permite exactamente una respuesta correcta; con otras palabras: la razón práctica no se contradice. Los discursos de aplicación incorporan aquel procedimiento con el que pretendemos desempeñar esta pretensión que alzamos con cada norma válida.

Por supuesto que nunca podremos alcanzar fácticamente esta idea de un sistema coherente de todas las normas válidas. En su establecimiento trabajamos en cada situación de aplicación, cuya descripción completa cambia la matriz de las normas que potencialmente colisio- 
nan entre sí. Si cada norma válida precisa de un complemento de todas las otras normas aplicables en una situación, entonces se cambia su significado en cada situación.

De este modo somos dependientes de la historia puesto que ella sólo nos produce situaciones imprevisibles, que nos fuerza cada vez a una interpretación diferente del conjunto de todas las normas válidas.

Desde la perspectiva de un observador, con este modelo se configura la imagen de una forma de vida consistente en un conjunto desordenado de principios válidos que son aceptados en gran parte por los participantes y que en cada situación de aplicación particular se ordena mediante un esfuerzo reconstructivo común que facilita una respuesta adecuada. Visto desde la perspectiva interna, el discurso de fundamentación sólo expresa el aspecto de validez del principio de imparcialidad, pero no puede generar un conjunto coherente de principios para todos los posibles casos de colisión. Aunque el discurso de aplicación hace valer el punto de vista de la adecuación imparcial, sin embargo tan sólo puede exigir la consideración completa de todos los rasgos de una descripción de la situación. Resulta claro que difícilmente llevaríamos a la práctica una orientación moral bajo estos requisitos. En lugar de este ideal disponemos de «paradigmas» o esquemas en los que las normas que aquí y ahora mantenemos por válidas se colocan en un orden transitivo. Porque un orden como el expuesto anteriormente no es construible sin referencia a las posibles situaciones de aplicación, contienen estos paradigmas descripciones generalizadas de situaciones de una determinada clase. Habitualmente recurrimos a tales órdenes sistematizados de un modo más o menos fuerte cuando solucionamos casos de colisión típicos y esperables. Constituyen un contexto de fondo en el que se insertan en cada caso nuestras apreciaciones de la situación y los correspondientes juicios morales prima facie. Junto con otros saberes culturales de orientación pertenecen estos paradigmas a la forma de vida en la que cada uno de nosotros nos encontramos. Así, entre las formas modernas de vida cada una ha solucionado a su manera la relación de prelación entre el principio de libertad e igualdad, sin que quepa afirmar que los correspondientes paradigmas son inmodificables ni que prescriban siempre una y la misma solución para cada caso de colisión. Al descargar a los participantes en una determinada práctica social de tener que contentarse con un desordenado conjunto de principios sólo aplicables prima facie, que deben ser aplicados en cada situación moralmente relevante en un discurso de aplicación de modo adecuado a una descripción completa, tales paradigmas son, por supuesto, también una fuente de prejuicios, valoraciones deformadas de la situación y, por consiguiente, de una aplicación parcial y unilateral de las normas válidas. Para que esto 
no pueda consolidarse a la larga, los paradigmas han de ser siempre criticables independientemente de cada forma de vida en referencia a dos aspectos de la idea de imparcialidad: con respecto a la validez de las normas particulares, si a la luz de las posiciones de intereses cambiadas ya no puede mantenerse la reciprocidad de la consideración de intereses; y con respecto a la relación de coherencia entre las normas particulares, si la descripción generalizada de la situación que sirve de base ya no es compatible con una descripción completa de la situación.

\section{Una propuesta para la interpretación del principio de coherencia en la teoría del derecho}

Por medio de las circunstancias de la situación de actuación se puede explicar que en una sociedad se formen paradigmas o esquemas, con los que el conjunto de principios válidos y compartidos en común se asocia de tal modo, que es posible una aplicación adecuada: también la aplicación de normas ha de tener lugar en condiciones de tiempo escaso y conocimiento incompleto, de tal manera que los afectados no pueden comenzar de nuevo un discurso de aplicación en cada situación. Las «instituciones» morales no surgen en situaciones que precisan de decisión bajo la presión de tiempo escaso y saber incompleto. Las situaciones de actuación se distinguen además por medio del rasgo de la «doble contingencia»: alter ha de poder prever que ego seguirá también fácticamente el conjunto de normas válidas y principios compartidos en común. En caso contrario, no sería presumible que alter se pudiera motivar racionalmente en sus actos por medio de normas válidas. Del principio moral de la ética discursiva se sigue, por tanto, la autorización de utilizar medios de producción de decisiones empíricas para garantizar un seguimiento fáctico general de las normas.

Pero tan sólo puede esperarse un seguimiento fáctico de una norma si en un momento y un lugar cualquiera se ha decidido que vale esta norma, si puede emitirse un juicio particular sobre en qué situación, por medio de qué destinatarios, de qué modo una norma válida puede aplicarse, y cuándo el motivo para el seguimiento fáctico del juicio particular puede producirse empíricamente. Escasez de tiempo, el estado incompleto del saber y la doble contingencia entre los actores conducen a la institucionalización del sistema jurídico.

Por supuesto, los mecanismos que pueden producir decisiones en los distintos niveles de establecimiento de normas, aplicación de normas y puesta en práctica, no pueden absorber el contenido procesal del principio moral. Aunque las normas válidas del derecho posi- 
tivo y las sentencias firmes, a diferencia de las normas y juicios morales, no pretenden que sean seguidas fácticamente por cada individuo sólo por motivos racionales. No pueden, sin embargo, excluir un reconocimiento y seguimiento motivado racionalmente. Éste no ocurre salvo en el caso de que cualquier individuo pudiera llegar al resultado basado en una argumentación moral de que hay buenas razones para el reconocimiento de la validez y adecuación de una norma. Por eso los procedimientos institucionalizados de establecimiento y aplicación de normas no pueden excluir una argumentación moral sobre la validez y adecuación de normas. De que modo esto es posible, deberá analizarse sólo para los discursos jurídicos de aplicación. Para ello es preciso delimitar ante todo el modo propio de la argumentación jurídica como un caso especial del discurso moral de aplicación: se trata de un caso especial del discurso práctico general.

\section{III.1. Crítica de la tesis del caso especial de Alexy}

Según Alexy el estatuto especial de la argumentación jurídica estriba en que se trata de una «fundamentación racional en el marco del ordenamiento jurídico vigente» ${ }^{18}$. Esta restricción institucional es por eso fundamentable en un discurso práctico: es exigible porque las reglas y formas del discurso práctico general definen un procedimiento de decisión que en numerosos casos no conduce a ningún resultado y que, si conduce a algún resultado, no garantiza una certeza definitiva. En este permanente «espacio de inseguridad» una sociedad no puede satisfacer su «necesidad de decidir». "Dada esta situación y la necesidad de decidir existente de hecho, es racional (esto es, fundamentable en un discurso práctico) ponerse de acuerdo en un procedimiento que limite el espacio de lo posible discursivamente de la manera más racional posible» ${ }^{19}$. Por eso parece racional institucionalizar el procedimiento legislativo y el de aplicación judicial del derecho, en los que se puedan tomar decisiones bajo condi-

${ }^{18}$ Robert Alexy: Teoría de la argumentación jurídica, Centro de Estudios Constitucionales, Madrid, 1989, págs. 208, 213 y 274. [Para la comprensión de este tercer apartado es conveniente tener en cuenta que el sustantivo alemán Geltung y el adjetivo correspondiente geltend incorporan simultáneamente las acepciones de vigencia y validez, y está última no sólo en su sentido formal, sino también en el normativo: por eso al hablar de «ordenamiento jurídico vigente (geltende Rechtsordnung)» también se está mentando su corrección normativa. Por otra parte, la lengua alemana dispone del término Gültigkeit para referirse exclusivamente a la idea de validez normativa (N. del T.)].

${ }^{19}$ Ibidem, pág. 350; e id. (nota 12), págs. 498 y ss. 
ciones crecientemente restrictivas. La argumentación jurídica se encuentra entre las normas dadas previamente y las sentencias judiciales sobre casos particulares.

Resulta problemático, desde luego, si se puede fundamentar desde la ética del discurso la necesidad de restringir los discursos prácticos generales con el argumento de que por razones estructurales son de resolución indefinida. Los discursos prácticos deben estar por principio en la situación de producir resultados definitivos. De lo contrario no tendría sentido fundamentar el principio de universabilidad de la ética discursiva como un principio moral. Otra cuestión es si se pueden cumplir los requisitos idealizados de una argumentación práctica racional también bajo las condiciones reales de presión de acción y decisión. El «espacio de inseguridad» constatado por Alexy se abre, pues, sólo si se contrasta el discurso con la necesidad fáctica de decidir. Ésta procede sobre todo de tres factores, que no pertenecen a la estructura del discurso: porque las decisiones deben producirse bajo condiciones que no se caracterizan solamente por los requisitos de la argumentación racional, sino por la escasez de tiempo, por el estado incompleto del saber y la doble contingencia.

A pesar de estas restricciones hay, según Alexy, una coincidencia parcial y estructural entre la argumentación jurídica y el discurso práctico general: también en la argumentación jurídica se formula con razones la pretensión de corrección, de suerte que existe una «coincidencia parcial» entre ambos modos de argumentación; además también están presentes en el discurso jurídico algunos de esos principios, reglas y formas de la argumentación, que pertenecen a los elementos integrantes del discurso práctico general, de suerte que en referencia a esto también se puede constatar una «coincidencia estructural» ${ }^{20}$. A continuación quiero mostrar, en primer lugar, (a) que no es la pretensión de corrección práctica (en el sentido de la ética discursiva) la que caracteriza a los argumentos jurídicos $\mathrm{y}$, en segundo lugar, (b) que exactamente aquellas reglas y formas que para el discurso práctico general no sólo son necesarias, sino también suficientes, no están presentes -con buenas razones- en la argumentación jurídica. Esto hace finalmente que la discursividad de la argumentación jurídica, que ha sido formulada por Alexy como justificación interna y externa, debe fundamentarse de otro modo. Mi tesis será que sólo con la ayuda de la distinción suplementaria entre fundamentación y aplicación puede fundamentarse por qué la argumentación jurídica debe tener lugar en cuanto discurso bajo condiciones restringidas.

${ }^{20}$ Alexy (nota 18), págs. 274 y ss. 
a) La pretensión de corrección de un enunciado normativo no se refiere en la argumentación jurídica a que «sean absolutamente racionales, sino sólo a que puedan ser fundamentados racionalmente en el marco del ordenamiento jurídico vigente ${ }^{21}$. A diferencia de esto la pretensión de corrección práctica en el sentido de la ética discursiva se refiere a la validez de una norma o a su reconocibilidad general. Si bien en el discurso práctico las normas se presentan como argumentos, sin embargo su pretensión de validez se virtualiza. Como ha sido anteriormente explicado, se debería indagar precisamente en el discurso si una norma polémica expresa un interés general recíproco.

Así entendida, la pretensión de corrección práctica no puede formularse al mismo tiempo por los enunciados normativos que hacen las veces de interpretaciones normativas $\mathrm{y}$ sus fundamentaciones en el marco de un ordenamiento jurídico vigente. Una «fundamentación racional en el marco del ordenamiento jurídico vigente» no puede ser ex definitione una fundamentación de validez. En la argumentación jurídica, más bien, se presupone la validez de las normas o del ordenamiento jurídico en su totalidad. De acuerdo con las reglas J.2.1 y J.2.2, introducidas por Alexy, la justificación interna se refiere a reglas válidas presupuestas universalmente ${ }^{22}$. Pero con eso se presupone un elemento esencial para el discurso de validez: la consideración recíproca de los intereses de todos los afectados. Si la argumentación jurídica presupone la validez de las reglas, los argumentos jurídicos no podrán formular la misma pretensión que aquéllos que se refieren a la validez de una norma polémica. De otro modo mantendríamos un discurso tan sólo sobre interpretaciones y no sobre normas. No tendría sentido fundamentar la corrección práctica de la interpretación de una norma practica correcta; al menos habría que decir algo más sobre ese «plus» de corrección práctica en la interpretación frente a la norma. El modelo de Alexy amenaza por eso con borrar la distinción entre la norma y sus interpretaciones. Él ve este mismo peligro, cuando reconoce que en el discurso práctico general «los enunciados normativos en cuestión deben ser absolutamente» racionales, mientras que en la argumentación jurídica pueden ser fundamentados racionalmente sólo «en el marco del ordenamiento jurídico vigente» ${ }^{23}$. Del «absolutamente» pende, por supuesto, toda la diferencia, pues lo que se expresa con «validez» en la ética discursiva no es otra cosa que la reconocibilidad por parte de absolutamente todos los afectados. Una fundamentación «en el marco» de

${ }^{21}$ Ib., pág.. 274.

${ }^{22} \mathrm{Ib}$., pág. 215.

${ }^{23} \mathrm{Ib}$., pág. 213 (cursivas de K.G.). 
un ordenamiento vigente puede ser, pues, tan sólo una fundamentación de la validez convencional. Alexy ve, pues, también lo mismo, que «una racionalidad ilimitada de la decisión jurídica» presupondría «la racionalidad de la legislación» ${ }^{24}$. Pero entonces la argumentación jurídica no puede ser un «caso especial», sino solamente un aliud. Alexy reconstruye la lógica de la argumentación jurídica sobre el modelo del discurso de fundamentación.

b) Concebida, sin embargo, la argumentación jurídica en analogía con el discurso de fundamentación, las restricciones específicas del derecho implican la abolición de la discursividad. Esto se muestra en lo que Alexy denomina «coincidencia estructural de reglas y formas» de ambas clases de discursos. Todas las reglas y formas, que Alexy enuncia, carecen de la referencia al principio de universabilidad, que como regla de argumentación es constitutivo del discurso práctico general.

Esto vale, en primer lugar, para las reglas y formas de la justificación interna, que según Alexy están justificadas como casos de aplicación del principio semántico de universabilidad en la versión de Hare (regla 1.3' ' $^{25}$. Tampoco bajo las reglas y formas de la justificación externa se encuentra nada que introduzca en la argumentación jurídica el principio de universabilidad propio de la ética discursiva como regla constitutiva.

Ahora bien, aunque estas reflexiones semánticas son una condición necesaria para el discurso -pertenecen a la «lógica» de la argumentación- ${ }^{26}$, sin embargo, para tales reflexiones semánticas es significativo que pueden llevarse a cabo monológicamente y no exigen discurso alguno. Suficiente para el discurso es sólo aquella variante del principio de universabilidad, que se aplica a la consideración recíproca de los intereses de todos los afectados. Esto sucede en Alexy bajo las «reglas de fundamentación» del discurso práctico general (regla 5.1.2), pero no bajo las reglas y formas de la argumentación jurídica. Según lo dicho hasta ahora, esto tampoco tendría que sorprender, porque la argumentación jurídica debe presuponer precisamente como dado aquello para cuya fundamentación fue concebido: la validez de una norma.

Puede discutirse ciertamente sobre qué condiciones deben cumplirse para poder hablar de una «coincidencia estructural». Que algu-

${ }^{24} \mathrm{Ib}$., pág. 274.

${ }^{25} \mathrm{Ib}$., pág. 219. Véase también Aulius Aarnio/Robert Alexy/Aleksander Peczenik: «Grundlage der juristischen Argumentation», en W. Krawietz/R. Alexy (eds.): Metatheorie der juristischen Argumentation (Schriften zur Rechtstheorie, Cuaderno 108), págs. 9 y ss.

${ }^{26}$ Habermas (nota 10), pág. 110. 
nas de las reglas y normas que pertenecen a la justificación interna o externa de los enunciados normativos jurídicos también figuren en el discurso práctico no fundamenta todavía una coincidencia de la clase que permite la calificación de la argumentación jurídica como un «caso especial». Si tan sólo el principio de universabilidad de la ética discursiva no sólo es necesario, sino también suficiente para la pertenencia de un tipo de argumentación al discurso práctico general, el discurso jurídico no puede tratarse de un caso especial, porque la única regla que constituye al discurso de fundamentación como tal no existe en la argumentación jurídica, y tampoco puede existir.

\section{III.2. Argumentación jurídica como caso especial del discurso moral de aplicación}

Este problema se resuelve si se considera la argumentación jurídica como un caso especial del discurso moral de aplicación. Para los discursos de aplicación se presupone ya ex definitione la validez de las normas. Bajo este presupuesto tiene sentido no sólo hablar de la argumentación jurídica como un discurso, sino también de una fundamentación racional en el marco del ordenamiento jurídico vigente. No se trata tampoco de una restricción del discurso práctico general, porque no se trata de la validez de normas o de enunciados normativos. Sin embargo, la presente restricción se encuentra en otro nivel: los discursos jurídicos de aplicación deben producir decisiones en condiciones de tiempo escaso y de saber incompleto. Esta «función de descargo» es desempeñada sobre todo por los enunciados de la dogmática.

Para la justificación interna basta generalmente con introducir sólo una regla de uso de las palabras que junto con una descripción de la situación posibilita el tránsito de una norma a la aplicación a la situación en la forma de un juicio particular. Como he intentado mostrar anteriormente en el punto II., la elección de una regla de uso de las palabras está además incrustada en un contexto pragmático, a través del cual se caracteriza al mismo tiempo como una regla de selección con respecto a la situación completamente descrita. Con esta reconstrucción se cambia ahora también el status de la justificación externa. La justificación externa se convierte en una forma de reflexión de la actuación selectiva, cuyas reglas y formas deben ser examinadas para saber si con su ayuda se puede justificar la pretensión de adecuación que formulamos con la aplicación de una norma. La función de estas reglas y formas consistiría en facilitar por vía discursiva una interpretación coherente de todas las normas aplicables prima facie. El peligro de una aplicación parcial y unilateral de 
las normas, que se encuentra asociado a la elección de una regla de uso de las palabras, no se puede excluir a través de reglas y formas que exclusivamente complican el principio semántico de universabilidad propuesto por Hare.

Si esta hipótesis es correcta, las denominadas por Alexy reglas y principios de la interpretación, de la argumentación dogmática y del uso del precedente así como los principios prácticos generales y argumentaciones empíricas, deberían reconstruirse de manera tal que recibieran su sentido de la tarea de justificar coherentemente una aplicación normativa a la vista de una situación descrita completamente. Así se podrían entender los cánones de la interpretación como reglas que prescriben la consideración de principios en la implantación de un significado. El papel del precedente como argumento para una argumentación guiada por principios en la aplicación de normas ha sido mostrado sobre todo por Dworkin y MacCormick ${ }^{27}$. Si los distintos casos pueden compararse en referencia a tales rasgos que permiten la aplicación de un principio común, esto sólo puede fundamentarse a través de una descripción completa de la situación, que posibilita una consideración de todos los principios que colisionan entre sí. Con los enunciados de la dogmática se puede dilucidar el carácter paradigmático de las interpretaciones coherentes en referencia a las descripciones generalizadas de la situación.

Distintas teorías del derecho han reconocido entretanto que el principio de coherencia juega en la justificación de las interpretaciones de normas al menos el papel de una condición necesaria. Se diferencian sobre todo por la importancia que prestan a ese principio en relación a los otros principios con los que se encuentra vinculado de modo complementario. A menudo se le asocia al más estricto principio de consistencia y a un principio normativo más sustantivo, que debe posibilitar una decisión entre dos conjuntos de principios justificados coherentemente que colisionan entre sí: MacCormick complementa el principio de coherencia con un principio consecuencialista de ponderación de los bienes colectivos; Aamio y Peczenik se refieren a la forma de vida de un auditorio que dispone de un orden preferencial de valores ${ }^{28}$; Dworkin defiende una teoría radical de coherencia según la cual la justificación coherente de una interpretación normativa es al mismo tiempo una condición suficiente para la única respuesta correcta. Claro está que él eleva la exigencia de coherencia a una tarea infinita que requeriría un «juez Hércules» con capacidades sobrehumanas $^{29}$.

${ }^{27}$ Dworkin (nota 1), págs. 182 y ss.; MacCormick (nota 1), págs. 155 y ss.

${ }^{28}$ MacCormick (nota 1), págs. 129 y ss.; Aarnio (nota 1), págs. 221 y ss.; id. y otros (nota 25), págs. 75 y ss.; Peczenick (nota 1), págs. 197 y ss.

${ }^{29}$ Dworkin (nota 1), págs. 177 y ss. 
La teoría dworkiniana de la interpretación coherente de principios es la que más se aproxima al modelo de argumentación aquí propuesto. Sin embargo, su radicalidad se suaviza porque el principio de coherencia se reconstruye como una regla de argumentación para los discursos de aplicación. Una importante consecuencia de esto es que el principio de coherencia no puede ser aplicado idealiter por un individuo. Con esto resulta superflua la imagen ideal de un «Hércules». La restricción del discurso de coherencia al discurso de aplicación tiene además la consecuencia de tener que renunciar a la pretensión de poder fundamentar también la corrección de normas con este principio. Esto sólo es posible en un discurso de fundamentación en el que se trate de la validez de una norma polémica. Un enunciado normativo particular puede pretender ser correcto si se apoya en una norma válida y en su adecuada aplicación.

(Traducción de Juan Carlos Velasco Arroyo) 